Prismatika: Jurnal Pendidikan dan Riset Matematika Vol. 4 No. 1 (2021)

p-ISSN: 2654-6140, e-ISSN: 2656-4181

http://ejurnal.budiutomomalang.ac.id/index.php/prismatika

\title{
PENERAPAN STUDENT TEAM ACHIEVEMENT DIVISIONS (STAD) MENGGUNAKAN ALAT PERAGA UNTUK MENINGKATKAN PRESTASI BELAJAR MATEMATIKA
}

\author{
Asri Putri Anugraini' ${ }^{1}$ Muflihah ${ }^{2}$ \\ IKIP Budi Utomo Malang ${ }^{1}$, MTS Miftahul Ulum Gondanglegi ${ }^{2}$ \\ asriputrianugraini89@gmail.com ${ }^{1}$, mtsmiftahul@yahoo.com²
}

\begin{abstract}
Abstrak
Perkembangan ilmu pengetahuan dan teknologi memungkinkan semua pihak bisa mendapatkan informasi dengan cepat berbagai sumber. Siswa mempunyai kemampuan membutuhkan pemikiran kritis, sistematis, logis, kreatif, dan kemauan bekerja sama yang efektif sehingga memungkinkan untuk terampil berpikir rasional. Hasil observasi awal dapat diketahui bahwasannya sebagian besar siswa mengalami kesulitan dalam memahami materi matematika, sehingga tampak jelas ketika guru bertanya tentang materi yang telah disampaikan, siswa masih terlihat bingung dengan materi yang disampaikan guru. Penyampaian materi pelajaran matematika masih menggunakan pembelajaran konvensional serta pemanfaatan/penggunaan media pembelajaran yang berupa alat peraga yang masih terbatas. Dari permasalahan yang ditemukan peneliti mengambil keputusan untuk menggunakan metode kooperatif tipe STAD dengan menggunakan alat peraga dari bahan bekas sebagai tindakan penelitian. Penelitian tindakan kelas ini difokuskan pada siswa kelas VIII MTs. Miftahul Ulum Gondanglegi pada materi bangun ruang kubus dan balok yang dilakukan oleh peneliti dengan dua siklus. Siklus I menunjukkan $20 \%$ siswa dinyatakan tuntas belajar, sisanya belum mencapai kriteria keberhasilan yaitu $80 \%$. Hal tersebut dikarenakan dari segi beberapa aktivitas yang meliputi pemberian kuis, diskusi kelompok, presentasi, mengerjakan soal tes masih belum memenuhi kriteria keberhasilan yang diharapkan karena kurangnya percaya diri, kurang komunikasi antar siswa dan guru saat diskusi dan presentasi, siswa masih takut bertanya dan takut menjawab sehingga tampak kurang kooperatif. Siklus II memberikan poin peningkatan individu berdasarkan kriteria yang ditentukan dalam metode kooperatif tipe STAD. Siswa menunjukan kemampuan bertanya, menjawab, dalam berdiskusi dengan kelompok. Siswa aktif dalam merangkai alat peraga kooperatif dalam kegiatan diskusi. Hasil belajar mengalami peningkatan mencapai $80 \%$.
\end{abstract}

Kata kunci: STAD, Alat peraga, Prestasi belajar

\begin{abstract}
The development of science and technology allows all parties to obtain abundant information quickly and easily from various sources and places in the world. Students have the ability to think critically, systematically, logically, creatively, and the willingness to work together effectively so that it is possible to be skilled in rational thinking. The results of initial observations can be seen that most students have difficulty understanding mathematical material, so it is clear when the
\end{abstract}

Dikirim : 21 September 2021, Diterima : 13 Oktober 2021, Diterbitkan : 21 Oktober 2021 
teacher asks about the material that has been delivered, students still look confused with the material presented by the teacher. The delivery of mathematics subject matter still uses conventional learning and the use/use of learning media in the form of teaching aids is still limited. From the problems found, the researcher decided to use the STAD type cooperative method by using mathematics property as a research action. This classroom action research was focused on class VIII MTs students. Miftahul Ulum Gondanglegi on the material of cube and cuboid which was carried out by researchers in two cycles. Cycle I showed that $20 \%$ of students had completed learning, the rest had not reached the success criteria, namely $80 \%$. This was because in terms of several activities which include giving quizzes, group discussions, presentations, doing test questions, they still do not meet the expected success criteria due to lack of confidence, lack of communication between students and teachers during discussions and presentations, students were still afraid to ask questions and were afraid to answer. So it seems less cooperative. Cycle II gives individual points of improvement based on the criteria specified in the STAD type cooperative method. Students show the ability to ask questions, answer questions, in group discussions. Students were active in assembling cooperative teaching aids in discussion activities. Learning outcomes have increased reaching $90.47 \%$.

Keywords: STAD, mathematics property, learning achievement

\section{PENDAHULUAN}

Pendidikan adalah segala sesuatu yang sudah terencana untuk menciptakan proses belajar yang baik bagi siswa secara aktif menumbuhkan semangat belajar yang ada pada dirinya dengan mengembangkan kepribadian, kecerdasan, akhlak, serta ketrampilan. Menurut Sutrisno (2016:29) Pendidikan juga merupakan media yang dapat membentuk kecerdasaran serta kepribadian manusia secara professional. Kemamupaun siswa yang terlihat masih rendah adalah kemampuan koneksi matematis. Menurut Sulistyaningsih, (2012:122) mengungkapkan bahwa pada umumnya masih rendah kemampuan siswa dalam mengkoneksi matematika. Rendahnya kemampuan koneksi matematika pada peserta didik menyebabkan prestasi siswa menurun.

Observasi di sekolah siswa mangatakan bahwa matematika sulit dipelajari, dan merupakan materi pelajaran yang membingungkan dialami oleh siswa kelas VIII MTs. Miftahul Ulum Gondanglegi. Menurut Suardi (2015: 100), kesulitan belajar adalah suatu keadaan yang mengakibatkan siswa menjadi sulit untuk belajar. Kesulitan belajar bisa disebabkan kesulitan siswa saat memahami materi yang disampaikan oleh guru. Menurut Khotimah (2017) sikap siswa terhadap proses pembelajaran selayaknya menjadi perhatian para pendidik. Permasalahan siswa yang terjadi di kelas VIII dalam 
penyampaian materi pelajaran matematika masih menggunakan pembelajaran konvensional serta pemanfaatan/penggunaan media pembelajaran yang masih terbatas, sehingga materi-materi dalam bidang studi matematika yang membutuhkan penyampaian secara konkret, seperti materi kubus dan balok tetap terkesan abstrak. Penggunaan alat peraga dalam proses belajar menjadi solusi untuk bisa memahami materi secara konkret sesuai konsep matematika. Menurut Ali Hamzah dan Muhlisrarini (2014: 65) mempelajari matematika kepada siswa dikelas, guru dan siswa ikut terlibat aktif disetiap kegiatan belajar matematika. Sehingga siswa merasa terbantu dan lebih senang dalam berpartisipasi guna mengembangkan setiap gagasan untuk pemecahan masalah serta bisa memanfaatkan alat peraga sebagai pendamping belajar matematika. Untuk mengetahui seberapa jauh mana kemamuan siswa dalam menguasai materi prestasi belajar menjadi upaya untuk mencapai kemampuan peserta didik, maka diakhir proses belajar diadakan kegiatan evaluasi pembelajaran. Tujuan dilakukan kegiatan evaluasi adalah untuk mengetahui seberapa efektif siswa dalam memahami materi dan menjadi tolak ukur keberhasilan guru saat mengajar perlu adanya evaluasi yang dilakukan secara terusmenerus. Menurut Rosyid Moh. Zaiful, dkk (2019: 9) mengartikan prestasi belajar yang dinyatakan dalam bentuk simbol, angka, huruf, maupun kalimat yang menunjukkan target siswa dari rangkain hasil suatu kegiatan pembelajaran yang disertai perubahan untuk mencapai hasil yang memuaskan. Prestasi belajar berpedoman pada hasil belajar siswa yang disertai perubahan tingkah laku menyangkut ilmu pengetahuan, sikap, ketrampilan dari setiap proses belajar (Mariskhana, 2019:78).

Mengatasi masalah yang ada dikelas peneliti menggunakan metode STAD sebagai solusi untuk menyelesaikan masalah dikelas VIII MTs. Miftahul Ulum Gondanglegi. Model pembelajaran STAD merupakan pembelajaran kooperatif yang yang dilakukan dengan mengelompokkan peserta didik menjadi beberapa kelompok kecil dengan kecerdasan yang berbeda agar tercitpta kerjasama yang baik untuk mencapai tujuan belajar (Huda, 2015: 201). Model pembelajaran kooperatif ini mendorong siswa untuk berkolaborasi melalui belajar kelompok dengan kecerdasan yang berbedabeda secara akademik maupun latar belakang terbentuk kerja sama satu sama lain untuk menguasai keterampilan yang sedang dipelajari (Amirudin dan Ilham,2019). Menurut Ariani,dkk (2018: 66) model STAD memiliki komonen terdiri dari presentasi kelas, tim, kuis, skor kemajuan individual dan kerjasama tim. Dengan menggunakan model STAD ini bisa menjadikan siswa aktif membuat keterampilan, menumbuhkan rasa percaya diri dalam 
mengembangkan kemampuan belajarnya, siswa aktif untuk berkomunikasi dengan teman kelompok serta menjalin kekompakan dalam kerjasama tim dan meningkatkan prestasi siswa.

\section{METODE PENELITIAN}

Penelitian ini menggunakan pendekatan kualitatif. Menurut Sugiyono (2018:26) metode penelitian kualitatif diartikan metode penelitian berpedoman pada filsafat postpositivisme, dipakai dalam menelusuri konsep alamiah, dimana peneliti sebagai instrument kunci, teknik pengumpulan data dilakukan secara trianggulasi (gabungan), analisis data bersifat induktif/kualitatif, dengan menekankan pemahaman. Peristiwa yang dimaksud dalam penelitian ini adalah peristiwa terjadi secara alami dengan aktivitas siswa kelas, yang berhubungan pada prestasi belajar siswa terhadap materi bangun ruang (kubus dan balok) dengan metode kooperatif tipe STAD menggunakan alat peraga. Subyek penelitian siswa kelas VIII MTs Miftahul Ulum Gondanglegi semester II tahun pelajaran 2020/2021 yang berjumlah 24 siswa. Penelitian ini bertujuan untuk memperbaiki cara belajar siswa dan meningkatkan aktifitas belajar yang nyaman dan menyenangkan. Oleh karena itu penelitian ini dikenal dengan penelitian tindakan kelas .

Penelitian tindakan kelas ini bertujuan untuk meningkatkan hasil belajar siswa. Menurut Suyadi dalam bukunya (2014:14) menyimpulkan bahwa "Penelitian Tindakan Kelas (PTK) adalah sebuah kegiatan belajar secara langsung yang sengaja dimunculkan dan melihat setiap aktifitas belajar di kelas secara bersamaan“. Bogdan dan Biklen (dalam Kunandar, 2012) penelitian tindakan merupakan pengumpulan informasi yang akurat di dirancang untuk menghasilkan perubahan sistem belajar siswa. Desain penelitian yang digunakan dalam penelitian menggunakan. Dari pengertian di atas dijelaskan bahwa PTK merupakan kegiatan refleksi diri peneliti atau guru dalam suatu situasi didalam kelas.

Desain PTK yang dikembangkan oleh Arikunto (2015:23) menyebutkan desain penelitian pada setiap siklus memiliki empat langkah, yaitu: perencanaan, pelaksanaan, pengamatan dan refleksi. Penelitian ini dilaksanakan 2 siklus dengan materi pembelajaran yang dipersiapkan dalam penelitian, meliputi materi bangun ruang sisi datar kubus dan balok yaitu ; (1) unsur-unsur kubus dan balok (2) jaring-jaring kubus dan balok (3) luas permukaan kubus dan balok (4) volume kubus dan balok (5) latihan soal untuk memantau pemahman siswa. Siswa melaksanakan pembelajaran dengan tahapan-tahapan STAD menggunakan alat peraga berua bekas 
kardus, kaleng susu dan lain-lain. Adaun tahapan model STAD menurut Slavin (dalam Ariani, 2018:66) model STAD, pembelajaran ini terdiri atas lima komponen utama, yakni: presentasi kelas, tim, kuis, skor kemajuan individual dan rekognisi tim.

Pengumpulan data digunakan sebagai bahan untuk menyusun suatu informasi, yang digunakan untuk keperluan dalam penelitian. Menurut Sugiyono (2012:53) teknik pengumpulan data diambil dari interview (wawancara), kuesioner (angket), observasi (pengamatan), dan gabungan ketiganya.

\section{HASIL DAN PEMBAHASAN}

Kegiatan awal penelitian, peneliti membentuk kelompok secara heterogen yang terdiri dari 3-4 orang siswa. Peneliti mengelompokkan secara heterogen untuk mengantisipasi siswa berkemampuan rendah agar tidak tertinggal jauh dari yang lain. Dari proses pembentukan kelompok, terbentuk 6 kelompok dari 24 jumlah siswa kelas VIII. Sebelum dilakukan tindakan peneliti menyebarkan lembar observasi kegiatan kepada pengamat penelelitian. lembar observasi kepada pengamat di awal sebelum penelitian dimulai bertujuan untuk pengamat memahami dan mengerti akan tugasnya. Tindakan penelitian nanti siswa akan diahadapkan dengan alat peraga. alat peraga sebagai pedoman untuk siswa dalam belajar yang efisien untuk tercapainya optimalitas dalam pembelajaran agar siswa mudah untuk mempelajari materi matematika (Ismawati,2016 : 233)

Siklus I dimulai dengan tahapan perencanaan, pelaksanaan tindakan , observasi dan refleksi, materi pembelajaran yang dipersiapkan dalam penelitian, meliputi materi bangun ruang sisi datar kubus dan balok yaitu ; (1) unsur-unsur kubus dan balok (2) jaring-jaring kubus dan balok (3) luas permukaan kubus dan balok (4) volume kubus dan balok (5) soal - soal latihan untuk mengetahui kemampuan siswa. Adapun tahapan metode kooperatif tipe STAD menggunakan alat peraga yaitu presentasi kelas, tim, kuis, skor kemajuan individual dan rekognisi tim. Berdasarkan hasil observasi aktivitas siswa pada pelaksanaan tindakan siklus I masih sangat kurang dikarenakan siswa tidak terbiasa dengan metode kooperatif tipe STAD sehingga terlihat kaku dan belum fokus dengan kegiatan berkelompok. Dapat terlihat bahwa siswa kurang percaya diri berkomunikasi didepan kelas dan masih kurang kompak dalam kerja sama tim. Hasil refleksi pada siklus I hasil tes menunjukkan $20 \%$ siswa yang tuntas belajar, yang belum mencapai kriteria keberhasilan yaitu sekitar $80 \%$. Hal ini dikarenakan dalam proses 
mengerjakan soal siswa tidak disiplin waktu serta kondisi kelas ramai sehingga ada beberapa soal belum terjawab.

Siklus II langkah-langkah pembelajaran sama dengan siklus I dimulai dari tahapan perencanaan, pelaksanaan tindakan, observasi dan refleksi. Siklus II ini membahas meteri tentang luas permukaan dan volume kubus dan balok. Pada siklus II terlihat perubahan siswa pada saat presentasi kelas, siswa sangat siap dan antusias selama belajar matematika mampu menjelaskan materi disertai demontrasi alat peraga. Alat peraga yang di buat oleh siswa terlihat menarik karena peneliti membebaskan siswa membuat mencari bahan dari barang yang tidak terpakai kemudian di modifikasi menjadi bentuk bangun ruang yang menarik. Kegiatan tersebut siswa tidak sendiri dalam membuat melainkan dilakukan secara bersama-sama dengan tim kelompoknya. Hasil refleksi ada siklus II menunjukkan prestasi siswa mengalami kenaikan $80 \%$.

\section{KESIMPULAN DAN SARAN}

Hasil analisis data pada kegiatan penelitian, menyimpulkan bahwa penerapan pembelajaran dengan metode kooperatif tipe STAD memamkai alat peraga dapat menjadikan prestasi sisswa meningkat sehingga belajar materi bangun ruang terlaksana dalam empat tahapan, yaitu: presentasi kelas, kerja kelompok, kuis dan rekognisi kelompok dengan tindakan 2 siklus. Sehingga penerapan metode kooperatif tipe STAD menggunakan alat peraga dapat meningkatkan presatasi belajar siswa materi bangun ruang.

Disarankan untuk peneliti berikutnya metode STAD sangat bisa di aplikasikan dengan alat peraga sebagai alternatif memudahkan belajar siswa dan membantu meningkatkan pemahaman siswa dan prestasi belajarnya. Pembelajaran kooperaif tipe STAD, dapat digunakan oleh guru mengingatkan pentingnya tanggungjawab individual, mengingatkan bahwa peserta didik memiliki banyak kesempatan untuk bisa sukses, perlu adanya penghargaan dari guru ketika siswasudah mencapai target yang diinginkan.

\section{DAFTAR RUJUKAN}

Ali Hamzah dan Muhlisrarini. 2014. Perencanaan dan Strategi Pembelajaran Matematika. Jakarta: PT. Rajagrafindo Persada

Amirudin dan Ilham. 2019. Meningkatkan Kualitas Pembelajaran Mtematika Melalui Penerapan Model Pembelajaran Kooeratif Tipe STAD dengan Pendekatan Saintifik. Jurnal Penelitian Matematika Dan Pendidikan Matematika (Proxima), 1(2), 25-32. 
Ariani, T., \& Agustini, D. (2018). Model Pembelajaran Student Team Achievement Division (STAD) dan Model Pembelajaran Teams Games Tournament (TGT): Dampak terhadap Hasil Belajar Fisika. SPEJ (Science and Physic Education Journal), 1(2), 65-77

Arikunto. 2015. Prosedur Penelitian Suatu Pendekatan Praktik, Jakarta: Rineka Cipta

Dahlia dan Suyadi.2014. Implementasi Dan Inovasi Kurikulum Paud 2013. Program Pembelajaran Berbasis Multiple Intelligences. Bandung: PT Remaja Rosda karya Belajar.

Huda, Miftahul. 2015. Cooperative Learning. Yogyakarta : Pustaka

Ismawati. 2016. Penggunaan Alat Peraga Untuk Meningkatkan Hasil Belajar Siswa Kelas V SD Negeri 29 Pagaralam Tentang Sifat-Sifat Bangun Ruang. JPPM, 9(2), 230-234

Khotimah, Sita Husnul. 2017. Pengaruh Penggunaan Metode Pembelajaran Terhadap Hasil Belajar Matematika Ditinjau Dari Sikap Siswa Pada Pelajaran Matematika. Jurnal HIKMAH, 8 (1), 95-114.

Kunandar. 2012. Langkah Mudah Penelitian Tindakan Kelas Sebagai Pengembanngan Profesi Guru. Jakarta: PT Raja Grafindo Persada

Mariskhana, Kartika. 2019. Prestasi Belajar Sebagai Dampak Dari Minat Baca Dan Bimbingan Belajar Siswa IPS. Cakrawala-Jurnal Humaniora, 19 (1), 71-79.

Moh. Suardi. 2015. Belajar \& Pembelajaran. Yogyakarta: Deepublish Nusantara

Rosyid, Moh. Zaiful, dkk. 2019. Prestasi Belajar. Jawa Timur : Literasi

Prof. Dr. Sugiyono. 2018. Metode Penelitian Kuantitatif, Kualitatif, dan $R \& D$. Bandung: Alfabeta

Sulistyaningsih, D. dkk. 2012. Model Pembelajaran Kooperatif Tipe CIRC dengan Pendekatan Konstruktivisme untuk Meningkatkan Kemampuan Koneksi Matematik. Unnes Journal of Mathematics Education Research, 1(2), 125-128.

Sugiyono. 2014. Metode Penelitian Kuantitatif, Kualitatif, dan Kombinasi (Mixed Methods). Bandung: Alfabeta

Sutrisno.2016. Berbagai Pendekatan Dalam Pendidikan Nilai Dan Pendidikan Kewarganegaraan. Jurnal Dimensi Pendidikan dan Pembelajaran 5(1), 28-31. 